\title{
The influence of coating damage on the ICCP cathodic protection effect
}

\author{
J. $\mathrm{Wu}^{1,2}, \mathrm{~S} . \mathrm{Xing}^{1,2} \& \mathrm{~F}$. Yun ${ }^{1,2}$ \\ ${ }^{I}$ State Key Laboratory for Marine Corrosion and Protection, P.R. China \\ ${ }^{2}$ Luoyang Ship Material Research Institute, P.R. China
}

\begin{abstract}
A one/hundredth scale hull model in linear scaled resistivity was used to simulate the cathodic protection potential distribution of a hull with different coating damage extent and position. The potential distribution of the hull was simultaneously measured by a PXI modular instrument and program written by Labview 7.1. At the same time, the potential and current density of the vessel with damage of $2 \%, 4 \%$ and $6 \%$ were calculated by the boundary element method (BEM). The results obtained from the physical scale model (PSM) method had agreement with the calculation results. The impressed current cathodic protection (ICCP) protection effect and its induced electric signature were simultaneously influenced by the coating damage extent and position. The damage extent mainly influenced the ICCP output current and the $\mathrm{x}$ axis' electric signature; the damage position mainly influenced the electric signature of the $y$ axis. Calculation results show that the electric signature increased about $35.7 \%$ due to coating damage of $6 \%$.
\end{abstract}

Keywords: cathodic protection, physical scale model, computer simulation, electric signature.

\section{Introduction}

Corrosion damage is a major factor in ship maintenance and availability. Coatings combined with the impressed current cathodic protection (ICCP) system are the most common means for shipboard corrosion control. They interact with each other to protect the shipboard. Coatings provide primary corrosion protection by isolating the hull metal from seawater, while ICCP systems protect the hull by applying an external source of current to the ship where the paint is damaged or degraded. 
The cathodic protective effect is related to the ICCP designed and coating state. Before the 1980s, the effect of ICCP systems designed by experience could not be exactly known. In the past decade, considerable effort has been spent in the development of rapid estimate and design methodologies that have a scientific rather than designer expertise basis. Two such methodologies are the physical scale model (PSM) and computational modelling using boundary element techniques [1].

The PSM technique has been developed to assess the performance of the ICCP systems installed on shipboards since the 1980s. It has been reported that directly proportional dilution of the seawater results in similar potential with reference to miniature electrodes placed along the side of the model as the actual potential on a full-size ship [2]. Apart from evaluation, this technique, which has been used to design ICCP systems installed on US Navy ships, could help in examining the relationships between the coating state and the ICCP protection affect, and optimize the initial position of anodes and reference electrodes. However, the PSM is only physical scale not chemical scale, so it is impossible to overcome the change in polarization behaviour in a scaled resistivity electrolyte [3]. In recent years, computer simulation technology has been developed for calculating the potential and current density distribution in electrochemical systems. Computer simulation techniques can rapidly obtain the potential and current density distribution on the hull with different coating states to estimate the impact of coating damage extent and position on the ICCP system. A primary limitation of computer simulation is the need for accurate and appropriate polarization response data [4], while the PSM does not require polarization response data. The concept of a unified approach between computational simulation and the PSM is very attractive, since it uses the strengths of each method to compensate for the weaknesses of the other [4]. The unified approach uses validated computational tools to examine hull geometry, boundary conditions and other parameters to define a relatively small set of experiments that can be completed in a time and cost efficient manner.

According to experience, the coating state plays an important role in the distribution of cathodic protective potential and the electric signature, but there were few reports about how the coating damage influences the potential signature distribution. In order to control the signatures and to preserve the integrity of a vessel, it is essential to predict the impact of the extent of the coating damage and the position of the electric fields and potential distribution. In this paper, PSM and boundary element method (BEM) technologies (BEASY10.0) were used to study the influence of the coating damage on the protective potential electromagnetic signature.

\section{Experimental}

\subsection{Physical scale model}

A vessel with a length of 125 meters was investigated. The ship had 250 frames with an interval of $0.5 \mathrm{~m}$ and the frames were assigned 0 to 250 from bow to 
stern. The scale model of the ship was a one/hundredth scale hull model with the same materials as the ship and the model was immersed in seawater diluted to the same scale ratio. The scale model was shown in Figure 1. The definition of the coating damaged position and area shown in Table 1 was based on observations of the ships in dry-dock after a period of service time. Throughout, the tests were performed at room temperature and potential measurements were made with eight $\mathrm{Ag} / \mathrm{AgCl}$ reference electrodes fitted with Luggin capillaries.

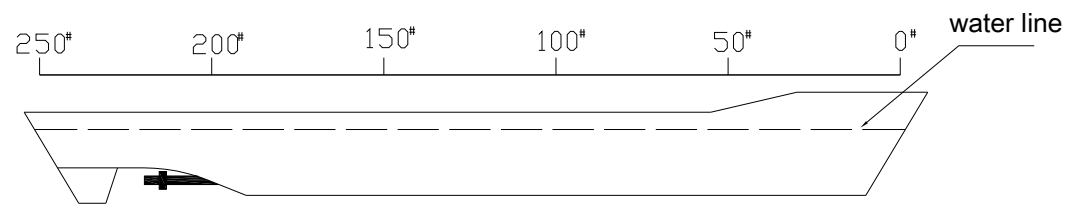

Figure 1: The physical scale model of vessel.

Table 1: $\quad$ Shipboard coating damage extent and position.

\begin{tabular}{cccc}
\hline Coating state & $2 \%$ damage & $4 \%$ damage & $6 \%$ damage \\
\hline Damage position & $\begin{array}{c}50^{\text {th }} \text { frame } \\
\text { (symmetrical) }\end{array}$ & $\begin{array}{c}120^{\text {th }} \text { and } 200^{\text {th }} \text { frame } \\
\text { (symmetrical) }\end{array}$ & $\begin{array}{c}50^{\text {th }}, 120^{\text {th }} \text { and } \\
200^{\text {th }} \text { frame } \\
\text { (symmetrical) }\end{array}$ \\
\hline
\end{tabular}

\subsection{Measurement system}

The protective potential of different positions on the vessel was simultaneously gathered by National Instruments and the Labview 7.1 program.

\subsection{Potential measurements}

The scale model was immersed in a sea water holding tank with the dimensions of $1.8 \mathrm{~m} \times 0.6 \mathrm{~m} \times 0.9 \mathrm{~m}$ and polarized to $-850 \mathrm{mV}$ for two days for the formation of calcium and magnesium deposition, and then the model was moved into diluted sea water with the conductance of $379 \mu \mathrm{S} / \mathrm{cm}$. The potential of the $10^{\text {th }}, 30^{\text {th }}, 50^{\text {th }}$, $70^{\text {th }}, 90^{\text {th }}, 110^{\text {th }}, 130^{\text {th }}, 150^{\text {th }}, 170^{\text {th }}, 190^{\text {th }}, 210^{\text {th }}, 230^{\text {th }}$ and $250^{\text {th }}$ were measured when the reference electrode potential was set at $-850 \mathrm{mV}$.

\subsection{Computer simulation}

The ship has two propellers and two rudders. The propellers were made of nickel-aluminium-bronze alloy (NAB) and modelled as solid disks with a surface area equivalent to the real propellers. The shaft is made of carbon steel and the propellers and shafts were assumed to be uncoated because of turbulence engendered by propeller movement. The ship's hull and rudders are also made of carbon steel, which were coated to prevent corrosion. The ICCP system evaluated included four anodes and a centre controlled power supply. The half of ship BEM model was shown in figure 2 . 


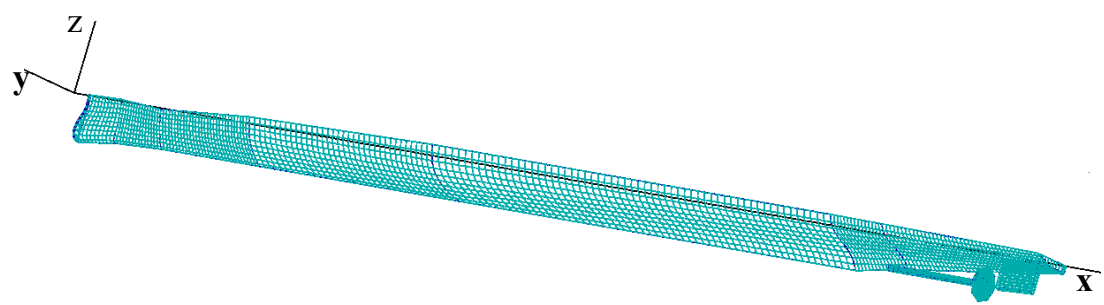

Figure 2: $\quad$ BEM model of ship.

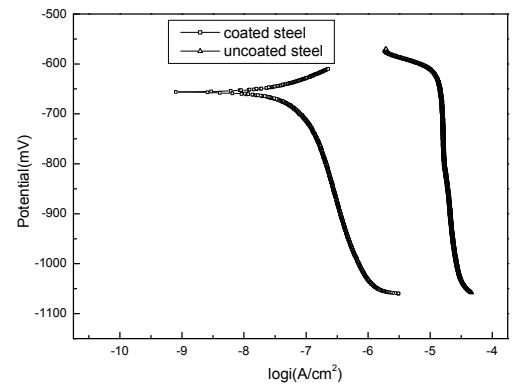

(a) carbon steel

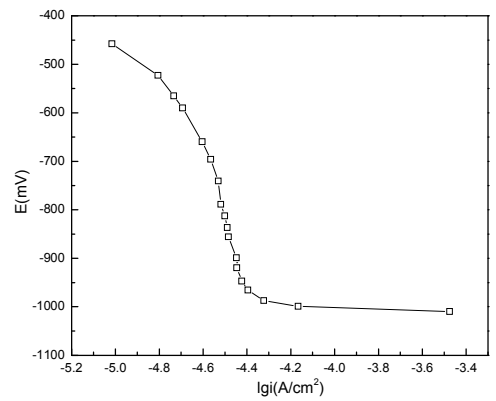

(b) NAB

Figure 3: Boundary condition.

The cathodic polarization curves of uncoated and coated carbon steel were shown in figure 3(a) and the polarization curve of NAB was shown in figure 3 (b), which was set as the boundary conditions of the ship model.

\section{Results and discussion}

\subsection{Potential simulation}

Former studies indicated that the ICCP system performed best when the anodes were symmetrically installed at the $130^{\text {th }}$ frame and the $232^{\text {nd }}$ frame and the reference electrode was installed at the $186^{\text {th }}$ frame. The hull of the ship was under sufficient protection, as shown in figure 4, when the coating was intact. The PSM measured data and computational results had good agreement with each other, except the anode zones. The difference between the PSM and the $\mathrm{BEM}$ at the anode zones was most likely due to the change in polarization of the materials in the diluted seawater, because the PSM supposes that dilution of the electrolyte does not significantly change the polarization behaviour of the materials [5]. 
When the coating was symmetrically damaged at the $50^{\text {th }}$ frame and the damaged area was about $2 \%$ of the whole underwater area, the potential distribution measured by the PSM experiment and calculated by computer simulation was shown in figure 5. According to the PSM experimental results and calculation data, the ICCP system can still provide enough cathodic protection to the hull with the potential ranged from $-800 \mathrm{mV}$ to $-1100 \mathrm{mV}$ when the reference electrode reads $-850 \mathrm{mV}$. Because the coating damage and damage positions are far away from the anodes, the potential at coating damage positions changed more positively in comparison with elsewhere.

Even though the coating damage area increased, it had little influence on the potential distribution, as shown in figure 6 . The hull was under protection and there was no potential wave in the coating damage regions. According to ohm law, the resistance is directly proportional to length, so if the coating damage position was neighbouring the anode, the potential of the uncoated steel could be easily polarized to the designed level, even though uncoated steel consumed more current than coated steel.

Similarly, the coating was symmetrically damaged at the $50^{\text {th }}$ frame, the $120^{\text {th }}$ frame and the $200^{\text {th }}$ frame, respectively, and the damaged area was in the same place, the potential variation at the $50^{\text {th }}$ frame was the biggest of the coating damaged regions as shown in figure 7 . So, for the ICCP system, when the coating damage extent was less than $6 \%$, the protective potential was mainly influenced by the coating damage position not the damaged area.
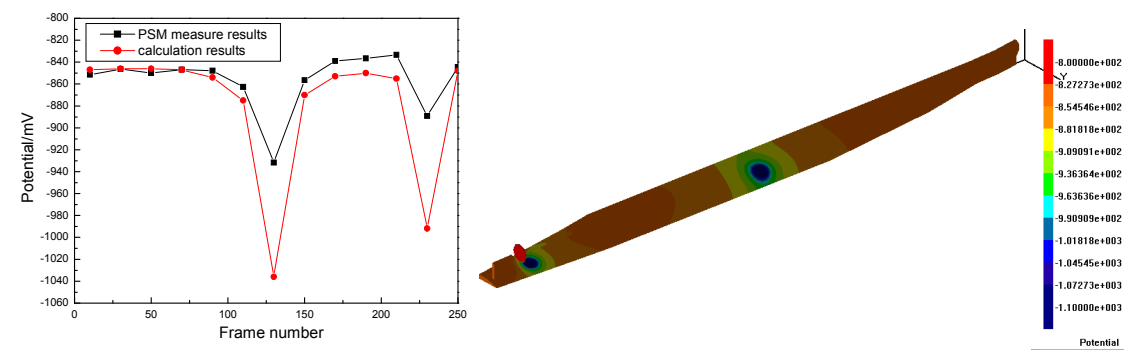

Figure 4: The potential $(\mathrm{mV})$ distribution of the ship's hull when the coating is perfect.

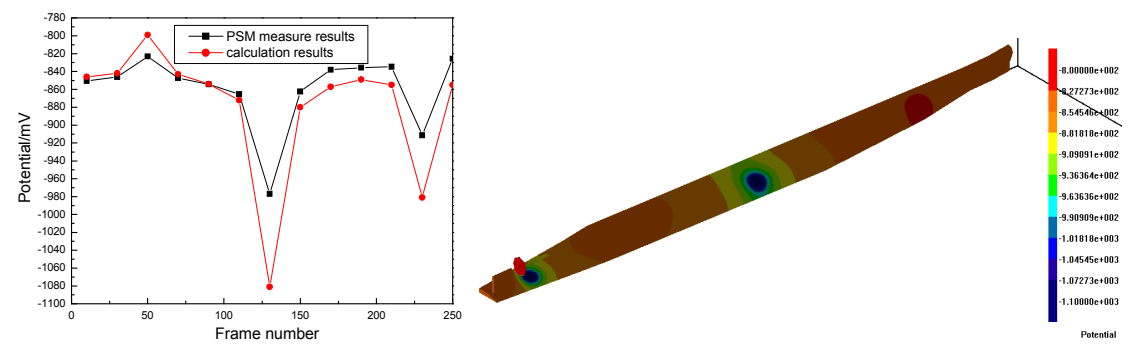

Figure 5: The potential $(\mathrm{mV})$ distribution of the ship's hull when the coating is $2 \%$ damaged. 

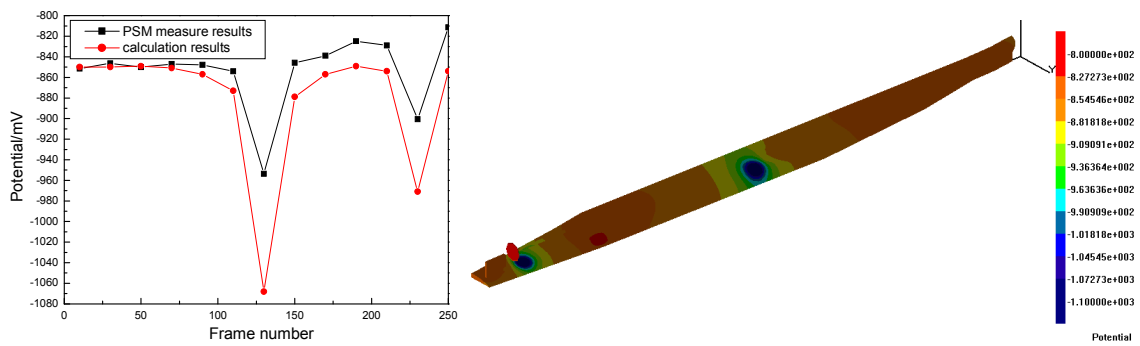

Figure 6: The potential $(\mathrm{mV})$ distribution of the ship's hull when the coating is $4 \%$ damaged.

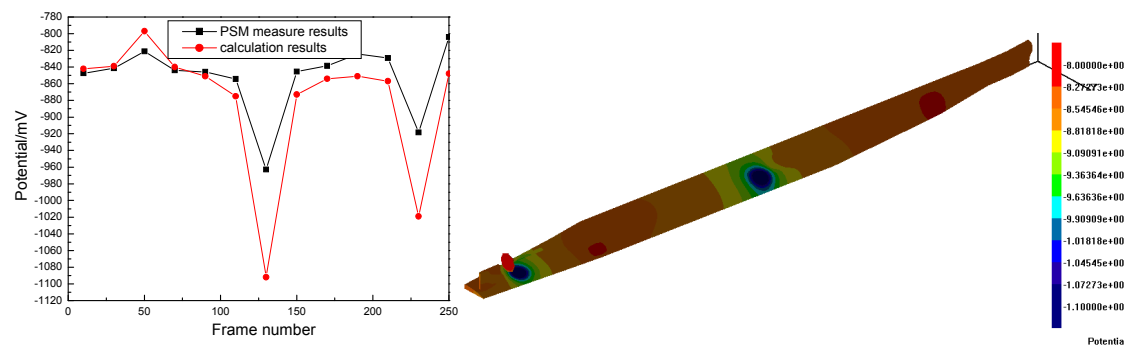

Figure 7: The potential $(\mathrm{mV})$ distribution of the ship's hull when the coating is $6 \%$ damaged.

\subsection{Electromagnetic signature simulation}

A line of sampling points was defined at a depth of $10 \mathrm{~m}$ beneath the sea level, and the vertical distance between simulation points and keel was about $10 \mathrm{~m}$. The solution at the sampling points along this line is used to compute the electric signature. The underwater potential was shown in figure 8 and the current density of the $\mathrm{x}, \mathrm{y}$ and $\mathrm{z}$ axes was shown in figure 9. According to the calculation results, the potential gradient near the anodes increased when the coating damage increased and the electric signature increased about $35.7 \%$ when the coating was $6 \%$ damaged, compared with perfect coating. Because the coating damage positions are far away from the anodes, the coating damage of the $50^{\text {th }}$ frame resulted in the potential gradient increasing in the bow region.

It is well known that the polarization current of uncoated steel is obviously larger than that of coated steel. So if the coating of the hull was damaged in some regions, the ICCP system must increase the output current to maintain the hull's potential under critical potential, and then the total output current increases with the damage extent increase. However, the current density of the $\mathrm{x}, \mathrm{y}$ and $\mathrm{z}$ axes distribution at the same time was influenced by the damage position. From figure 9 we know that the $\mathrm{x}$ axis' current density was mainly influenced by the damage extent, the current density of the $y$ axis was mainly influenced by the damage position and the $\mathrm{z}$ axis' current density was influenced by both damage extent 


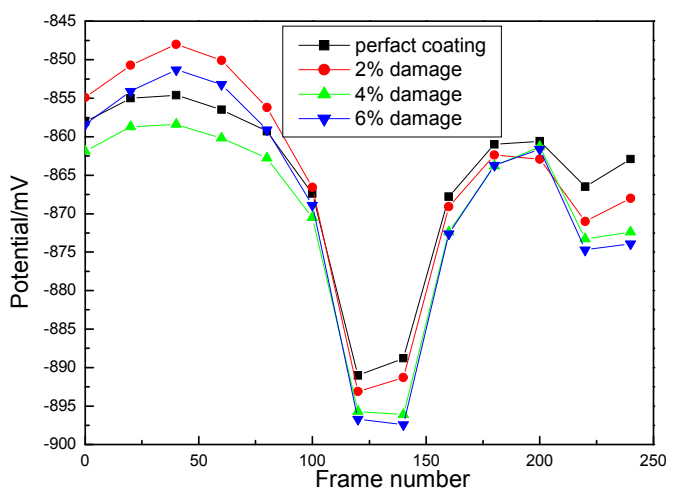

Figure 8: Underwater potential distribution along the keel.

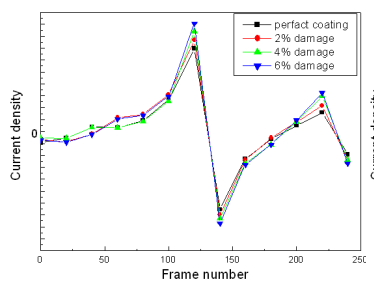

(a) $\mathrm{x}$ axis

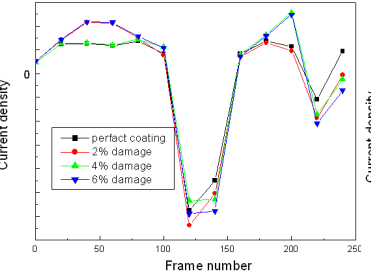

(b) y axis

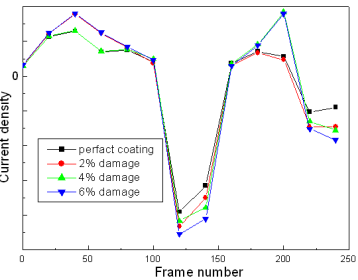

(c) z axis

Figure 9: Current density distribution along the keel.

and position. That is to say, the coating damage extent may result in the electric signature increasing along the vessel and the bow's coating damage may induce the electric signature to increase in the vertical orientation.

\section{Conclusions}

According to the PSM and computer simulation studies, the ICCP protection effect and its induced electric signature were simultaneously influenced by the coating damage extent and position. The potential gradient and electric signature increased with the increase of the coating damage area and the electric signature increased by about $35.7 \%$ when the coating damage area extended to $6 \%$. The damage extent mainly influenced the ICCP output current and $\mathrm{x}$ axis' electric signature and the damage position mainly influenced the electric signature of the $\mathrm{y}$ axis.

\section{References}

[1] DeGiorgi V.G, Thomas E.D, Lucas K.E and Kee A. A combined Design Methodology for Impressed Current Cathodic Protection Systems. Boundary Element Technology XI, Computational Mechanics Pub. 1996: 335-345 
[2] R. W. Ditchfield, J. N. McGrath and D. J. Tighe-Ford. Theoretical validation of the physical scale modelling of the electrical potential characteristics of marine impressed current cathodic protection. J. Applied Electrochemistry. 1995.25:54-60

[3] I. Gurrappa. Physical and Computer Modelling for Ship's Impressed-current Cathodic-protection Systems.

[4] V.G. DeGiorgi, S.A. Wimmer, E. Hogan and K.E. Lucas. Modelling the experimental environment for shipboard ICCP systems. Boundary Elements XXIV: 440

[5] N Gage and P Mart. Further Cathodic Protection Studies of Naval Ships[J].CAP.2002:1-13 